\title{
Verbal Anti-Agreement with Non-Human DPs
}

\author{
Feras Saeed ${ }^{1}$ \\ ${ }^{1}$ Associate Professor of Theoretical Linguistics, College of Sciences \& Arts, Qassim University, Saudi Arabia \\ Correspondence: Feras Saeed, Department of English, College of Sciences \& Arts-Unaizah, Qassim University, \\ Saudi Arabia. E-mail: ferasaeed@yahoo.com
}

Received: August 4, 2019 Accepted: September 1, 2019 Online Published: September 6, 2019

doi:10.5539/ijel.v9n5p362 URL: https://doi.org/10.5539/ijel.v9n5p362

\begin{abstract}
This paper examines the unexpected verbal anti-agreement with non-human plural subjects in Standard Arabic. In this language, when the plural subject denotes non-humans, the verb fails to establish plural agreement with that subject. Non-human DPs refer to nominals which denote any animate life-form other than humans as well as all inanimate entities. In this paper, I provide two competing analyses to account for this phenomenon. In the first analysis, I build on the assumption (Mohammad, 2000) that preverbal subjects in this language are Topics and argue that the singular number marker on the anti-agreeing verb is the result of establishing partial agreement with the non-human subject in its base-position before movement/dislocation to TopP. In the second account, I borrow Corbett's (2004) notion of 'individuated nominals' where it is assumed that plural nominals can either refer to collective individuals or distinct individuals; subsequently the intended referent dictates agreement on the verb. Hence, I argue that non-human plural subjects are collective nominals that are not individuated, therefore they are inherently singular and the plural marker in this case carries morphosyntactic information that does not affect the inherently imposed singular feature.
\end{abstract}

Keywords: verbal anti-agreement, non-human subjects, individuated nominals, Standard Arabic

\section{Introduction}

In Standard Arabic, partial agreement in person and gender holds between the verb and the subject in VS order as in (1a). Full verbal agreement in VS order yields the ungrammatical sentence in (1b). In SV order, full agreement in person, number, and gender holds between the subject and the verb as in (2a). The sentence in (2b) is ungrammatical since the verb displays partial agreement in SV order. In other words, when the subject is postverbal, the number feature on the subject does not agree with the number feature on the verb and the latter shows a default singular number marker:
(1)
a. ћaDar-a
T-Tullaab-u
n-nadwat-a (Note 1)
attended-3.s.m
the-students-nom
the-seminar-acc
'The students attended the seminar'
b. *haDar-uu
T-Tullaab-u
n-nadwat-a
attended-3.p.m the-students-nom
the-seminar-acc
'The students attended the seminar'
(2) a. PaT-Tullaab-u haDar-uu
the-students-nom attended-3.p.m
'The students attended the seminar'
n-nadwat-a
the-seminar-acc
b. *RaT-Tullaab-u haDar-a n-nadwat-a
the-students-nom attended-3.s.m the-seminar-acc
'The students attended the seminar'

This classical and extensively studied asymmetrical pattern of subject-verb agreement in Standard Arabic does not seem to apply to the agreement context when the plural subject of the verb refers to a non-human nominal. In this context, the verb, invariably, surfaces with a singular number marker whether the subject is singular or plural and whether it is preverbal or postverbal: 
(3)
a. Taarad-at
il-qiTaT-u
1-fi?raan-a
chased-3.s.f the-cats-nom the-rats-acc

(VS)

'The cats chased the rats'

b. *Taarad-na 1-qiTaT-u 1-fi?raan-a

chased-3.p.f the-cats-nom the-rats-acc

'The cats chased the rats'

(4) a. Pal-qiTaT-u Taarad-at il-fi?raan-a

the-cats-nom chased-3.s.f the-rats-acc

'The cats chased the rats'
b. *?al-qiTaT-u
Taarad-na
1-fi?raan-a
the-cats-nom
chased-3.p.f the-cats-acc
'The cats chased the rats'

The paper is divided as follows: in the second section, I describe the verbal anti-agreement facts with non-human plural subjects in Standard Arabic in their different contexts. In the third section, I provide a brief overview of the literature on verbal anti-agreement with non-human DPs in other languages. In the fourth section, I look at the distribution of non-human DPs in Standard Arabic. In the fifth section, I provide a survey of the different agreement contexts for non-human DPs. In the sixth section, I revisit the phenomenon of verbal anti-agreement with non-human plural subjects in this language and provide two competing explanations to account for this instance of defective agreement. In the last section, I summarise the main conclusions and findings of the paper.

\section{Verbal Anti-Agreement Facts}

There is a type of nominals in Standard Arabic that has often been left out in previous approaches to agreement asymmetry in Standard Arabic, due to its problematic pattern of agreement. The type of nominals in question is the non-human plural subject. In Standard Arabic, when the subject is a non-human plural DP, the verb fails to establish number agreement with that subject. Unlike the canonical subject-verb agreement pattern in Standard Arabic where the verb usually establishes full agreement with its subject when the latter precedes the verb in SV word order, the verb always shows a singular number marker when its subject refers to a non-human nominal, regardless of the position of the subject:
(5) a. Taarad-at il-qiTaT-u l-firraan-a
chased-3.s.f the-cats-nom the-rats-acc
'The cats chased the rats'
b. *Taarad-na 1-qiTaT-u 1-fi?raan-a
chased-3.p.f the-cats-nom the-rats-acc
'The cats chased the rats'
c. habaT-at iT-Taa?iraat-u Sala 1-midraj-i
landed-3.s.f the-planes-nom on the-runway-gen
'The planes landed on the runway'
d. *habaT-na T-TaaPiraat-u Cala 1-midraj-i
landed-3.p.f the-planes-nom on the-runway-gen
'The planes landed on the runway'
(6) a. *2al-qiTaT-u Taarad-na 1-fi?raan-a
the-cats-nom chased-3.p.f the-cats-acc
'The cats chased the rats'
b. Pal-qiTaT-u Taarad-at il-firraan-a
the-cats-nom chased-3.s.f the-rats-acc
'The cats chased the rats' 


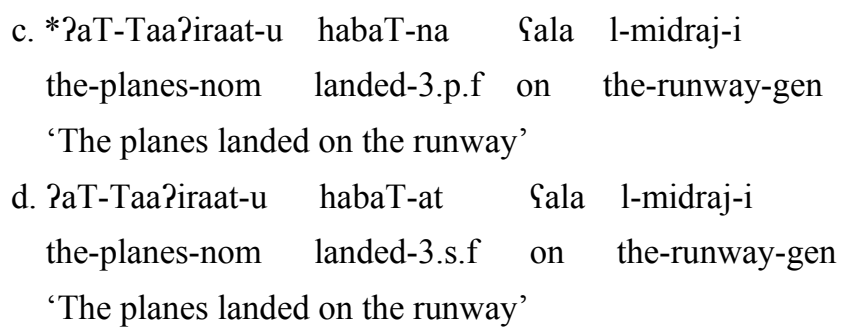

To complicate the matter further, it should be noted that subject-verb agreement must have taken place between the verb and its non-human plural subject, given the fact that the verb surfaces with a feminine marker. It should be mentioned here that all non-human plural DPs have an inherent feminine gender, invariably, regardless of the gender of the singular nominal which might happen to be masculine:

$\begin{array}{llll}\text { (7) a. } & \text { shareb-a } & \text { 1-jamal-u } & \text { 1-maaP-a } \\ & \text { drank-3.s.m } & \text { the-camel-nom.m } & \text { the-water-acc }\end{array}$

'The camel drank the water'

b. shareb-at il-jimaal-u 1-maa?-a

drank-3.s.f the-camels-nom.m the-water-acc

'The camels drank the water'
c. *shareb-a
l-jimaal-u
1-maa?-a
drank-3.s.m the-camels-nom.m the-water-acc

'The camels drank the water'
(8) a. Pal-jamal-u shareb-a 1-maa?-a
the-camel-nom.m drank-3.s.m the-water-acc

'The camel drank the water'
b. Pal -jimaal-u shareb-at il-maa?-a
the-camels-nom.m drank-3.s.f the-water-acc
'The camels drank the water'
c. * Pal -jimaal-u shareb-a 1-maa?-a
the-camels-nom.m drank-3.s.m the-water-acc

'The camels drank the water'

Furthermore, non-human dual subjects do not demonstrate this agreement discrepancy and they show regular pattern of agreement similar to human DPs:
(9) a. nabah-a
1-kalb-aan
barked-3.s.m the-dog-dual-nom
'The (two) dogs barked'
b. Pal-kalb-aan nabah-aa
the-dog-dual-nom barked-3.dual.m
'The (two) dogs barked'

Almost all the approaches to subject-verb agreement asymmetry in Standard Arabic skipped citing any data which involve non-human plurals for the sole fact that when these DPs are pluralized, they exhibit unexpected patterns of anti-agreement in different contexts.

Non-human DPs refer to nominals which denote any entity other than human beings. In this case, non-human DPs include all inanimate entities whether concrete, e.g., cars, computers, mountains, guns, etc., or abstract, e.g., identities, emotions, thoughts, etc. Non-human DPs also include all animate life-forms, other than humans, whether real/worldly, e.g., dogs, cats, lions, elephants, etc., or ethereal, e.g., angels, ghosts, demons, etc. In spite of the fact that non-human DPs represent the majority of nominals in Standard Arabic, or any other language for that matter, the literature on agreement in Standard Arabic seems oblivious to their lexical properties and 
agreement patterns.

Non-human DPs inflect for number, gender, Case, and definiteness. These DPs have three grammatical numbers: singular, dual, and plural. Intuitively, non-human DPs lack first person and second person features and have only third person feature. Moreover, these DPs have two forms for gender, i.e., masculine and feminine, and can be definite or indefinite.

\section{Brief Overview of the Literature on Verbal Anti-Agreement with Non-Human DPs}

It has been argued in the literature that plurality draws a dichotomy between two types of nominals in any single language, where languages vary from each other in the type of feature they choose from a hierarchy of features based on animacy (Smith-Stark, 1974; Allan, 1987; Comrie, 1989; Corbett, 2004).

The animacy hierarchy was first proposed by Smith-Stark (1974) and then Corbett revised this hierarchy to include the following features (2004, p. 56):

(10) speaker $>$ addressee $>3$ rd person $>$ kin $>$ human $>$ animate $>$ inanimate

Corbett provides an extensive survey of many languages of the world where he shows that this animacy hierarchy actually divides the nouns in these languages into two types. He looks at how languages choose a certain feature from this hierarchy to be the parameter for splitting their class of nouns into two types. This 'split' in nominals is either reflected in the inflection of the nouns or in the agreement relation between the noun and the verb. For the purposes of this study, we will restrict our discussion here to the feature 'human' in order to understand how the languages of the world treat 'human/non-human' nominals in agreement contexts.

The first language we look at is the Hare dialect of Slave, a language spoken in Canada. It is argued that in this language certain class of nouns have the suffix '-ke' which is a plural or group morpheme. This suffix can optionally appear at the end of these nouns, provided that these nouns denote humans. Therefore, only nouns referring to human beings can have plurals (Rice, 1989, p. 247):

$\begin{array}{rll}\text { (11) a. } & \text { se-ya } & \text { se-ya-ke } \\ & \text { 1.s-son } & \text { 1.s-son-p } \\ & \text { 'my son' } & \text { 'my sons' } \\ \text { b. } & \text { t'eere } & \text { t'eere-ke } \\ \text { girl } & \text { girl-p } \\ \text { 'girl' } & \text { 'girls, group of girls' }\end{array}$

In Mayali, a language spoken in Australia, pronominal objects and subjects can be prefixed on the verb, and the verb can establish agreement with the object pronoun. However, plural number is marked on the verb only when the object pronominal denotes humans (Evans, 1995, p. 213):
(12) abanmani-na-ng bininj
s.p-see-PAST.PRFV man
'I saw the two men'

When the object pronoun refers to a non-human, the verb shows singular number:

$\begin{array}{cll}\text { (13) Duruk } & \text { ginga } & \text { ba-bayeng } \\ \operatorname{dog} & \text { crocodile } & \text { s.s-bite.PAST.PRFV }\end{array}$

'The crocodile has eaten all the dogs'

In Muna, a language spoken in Indonesia, plural nouns/pronouns denoting humans take plural agreement (Berg, 1989, pp. 51-52):

(14) ihintu-umu o-kala-amu

2-p 2-go-p

'You go'

However, nouns denoting in animates take singular agreement:

$\begin{array}{ll}\text { (15) bara-hi-no no-hali } \\ \text { good-p-his } & \text { 3.s-expensive }\end{array}$

'His goods are expensive' 
In Miya, a West Chadic language, plural nouns denoting humans and domesticated animals take plural agreement (Schuh, 1998, p. 197):

$$
\begin{aligned}
& \text { (16) niykin dzafə } \\
& \text { this-p man-p } \\
& \text { 'These men' }
\end{aligned}
$$

On the other hand, when the plural noun denotes a non-human/inanimate, it does not take plural agreement. Instead, it takes agreement according to its gender in the singular:

$$
\begin{aligned}
& \text { (17) nakən viyayuwawaw } \\
& \text { this-s.m fireplace-p } \\
& \text { 'These fireplaces' }
\end{aligned}
$$

Corbett (2004) explains the mismatch in the number feature between the subject and the verb, especially in cases where the verb fails to show plural agreement marker with a plural subject, in terms of the animacy hierarchy and that languages choose different points in this hierarchy to classify their nominals. The effect of this classification can appear in the inflection of the noun or in its agreement relation with the verb. He also introduces the notion of 'individuation', which he borrows from Wright (1967). Wright, in his discussion of the dichotomy between broken plurals and sound plurals, argues that the irregular plural in Arabic denotes individuals viewed collectively, whereas the regular plural refers to distinct individuals. Corbett $(2004$, p. 209) builds on Wright's assumption by claiming that:

"if this distinction survives at least partially, then the agreements are understandable: the sort of noun which has a sound plural is that where the referent is likely to be individuated. Hence it is not the morphological form which is directly determining the agreement; rather the morphological form is an indicator of the type of noun we are dealing with."

To account for this agreement mismatch, Corbett (2004, pp. 216-217) puts forth the assumption that:

"the larger the numeral in a subject numeral phrase, the smaller the chance of it taking a plural predicate. The groups which we quantify with larger numbers are the groups which are less individuated and conversely are more likely to be viewed as a unit. And as a result, when there is a choice of agreement, the higher numerals are more likely to be treated somewhat more like nouns and control singular agreement... the more individuated the subject the more likely plural agreement becomes."

\section{Distribution of Non-Human DPs}

Non-human DPs can be the subject of a verbal clause or its object, and can be marked for Case:
(18) qatal-at in-numuur-u S-Saiyyaad-a
killed-3.s.f the-tigers-nom the-hunter-acc
'The tigers killed the hunter'
(19) qatal-a S-Saiyyaad-u n-numuur-a
killed-3.s.m the-hunter-nom the-tigers-acc

'The hunter killed the tigers'

Non-human subjects can also surface preverbally, which is the typical full agreement context in this language, similar to human DPs:
(20) Pan-numuur-u qatal-at fiil-an
the-tigers-nom killed-3.s.f elephant-acc

'The tigers killed an elephant'

Further, it is to be noticed that in Standard Arabic when the verb is passivised, the object is assigned a nominative Case in-situ:
(21) qutil-a
1-junuud-u
got killed-3.s.m the-soldiers-nom
'The soldiers were killed'

Full agreement on the passivised verb triggers the movement of the object to a preverbal position: 
(22) Pal-junuud-u qutil-uu

the-soldiers-nom got killed-3.p.m

'The soldiers were killed'

Similarly, non-human DPs can also surface with a passivised verb in both word orders:

(23) qutil-a l-fill-u

got killed-3.s.m the-elephant-nom

'The elephant was killed'

(24) Pal-fiil-u qutil-a

the-elephant-nom got killed-3.s.m

'The elephant was killed'

Moreover, non-human DPs can be the subject of a verbless clause in Standard Arabic:
(25) Pal-fiil-u
mariiD-un
the-elephant-nom sick-nom
'The elephant is sick'
(26) Pan-numuur-u jaaii̧at-un
the-tigers-nom hungry-nom
'The tigers are hungry'

\section{Agreement Contexts for Non-Human DPs}

Non-human DPs can agree with verbs, demonstrative pronouns, adjectives, relative pronouns, and pronominal clitics. Before examining verbal agreement with non-human DPs, which is the main topic here, let us look at the different contexts in which a non-human DP can establish agreement, and the featural specification of the agreement relation.

\subsection{Non-Human DPs and Copular Predicates}

In what looks like copular sentences in Standard Arabic, the verb yakuun 'is' cannot surface overtly; therefore, such constructions are called verbless sentences. However, in these sentences the subject DP agrees with the predicate in number, and gender. Moreover, the subject DP as well as the predicate inflect for nominative Case:
(27) Pal-walad-u mariiD-un
the-boy-s.m.nom
sick-s.m.nom
'The boy is sick'
(28) Pal-Pawlaad-u$$
\text { mariiD-uun }
$$
the-boys-p.m.nom
'The boys are sick'

However, the past tense form of the copula, i.e., kaan 'was', does actually surface overtly:

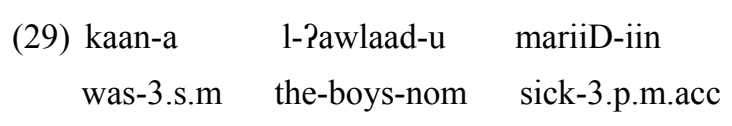

'The boys were sick'

(30) Pal-Pawlaad-u kaan-uu mariiD-iin

the-boys-nom were-3.p.m sick-3.p.m.acc

'The boys were sick'

When the copular verb is overt, it behaves like other verbs in the language, i.e., it establishes partial or full agreement with the subject depending on the latter's position (Benmamoun, 2000). Moreover, the predicate mariiD 'sick' is assigned accusative Case. However, it is to be noticed that while the copular verb shows agreement with the subject DP, the latter obligatorily agrees with the predicate mariiD 'sick'. A thorough investigation of this pattern of agreement is beyond the scope of this paper. What is relevant here is that a non-human DP can also surface as the subject of a verbless sentence in Standard Arabic: 


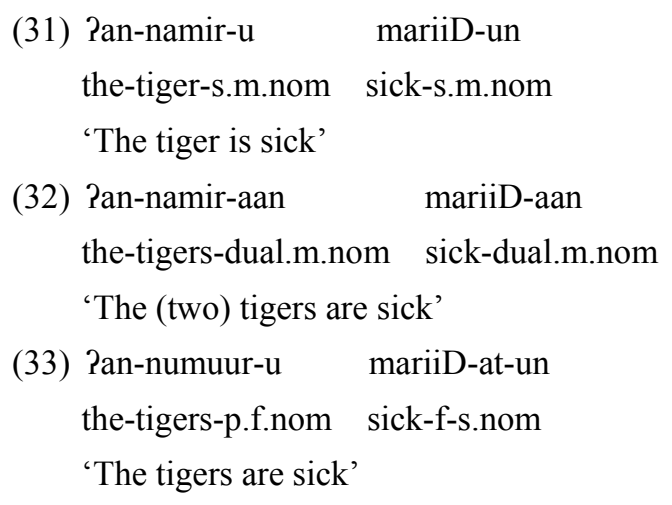

It is to be noted from the examples above that while the singular and dual forms of non-human DPs retain their number when they agree with the predicate, the plural form in (33) loses its plural number and this can be seen in the singular agreement feature on the predicate. It is clear from the examples above that when a non-human DP is pluralized, its number is demoted to the singular.

The same pattern of agreement can also be found in sentences where the past tense form of the copula kaan 'was' is overt:
(34) kaan-a
n-namir-u
mariiD-an
was-3.s.m
the-tiger-s.m.nom
sick-s.m.acc

'The tiger was sick'
(35) Pan-namir-u kaan-a mariiD-an
the-tiger-s.m.nom was-3.s.m sick-s.m.acc
'The tiger was sick'
(36) kaan-a n-namir-aan mariiD-ain
was-3.s.m the-tigers-dual.m.nom sick-dual.m.acc

'The (two) tigers were sick'
(37) Pan-namir-aan kaan-aa mariiD-ain
the-tigers-dual.m.nom were-3.dual.m sick-dual.m
'The (two) tigers were sick'

(38) kaan-at in-numuur-u mariiD-at-an

was-3.s.f the-tigers.p.f.nom sick-f-s.acc

'The tigers were sick'
(39) Pan-numuur-u kaan-at mariiD-at-an
the-tigers-p.f.nom was-3.s.f sick-f-s.acc
'The tigers were sick'

It is clear that the non-human DP cannot establish plural agreement with the verb in any word order. It agrees with the copula kaan 'was' as well as the predicate mariiD 'sick', but the agreement morphology on both the copula and the predicate shows a singular number, although the form of the non-human DP is plural.

\subsection{Non-Human DPs and Demonstrative Pronouns}

Standard Arabic has the following demonstrative pronouns: this, that, these, and those. However, these pronouns inflect for gender and number, giving an array of ten different forms of demonstrative pronouns. Non-human DPs participate in concord with demonstrative pronouns in number and gender. When the demonstrative pronoun has a dual number feature, it is usually marked for Case:
(40) haath-a 1-kalb-u
kabiir-un
this-s.m the-dog-s.m.nom big-s.m.nom
'This dog is big'
(41) haath-aan
il-kalb-aan
kabiir-aan 
these-dual.m.nom the-dogs-dual.m.nom big-dual.m.nom

'These (two) dogs are big'

(42) haath-ih il-kilaab-u kabiir-at-un

this-s.f the-dogs-p.f.nom big-f-s.nom

'These dogs are big'

(43) *haa?ulaa? il-kilaab-u kabiir-aat-un

these-p.m/f the-dogs-p.f.nom big-p.f-nom

'These dogs are big'

In the singular and dual forms, the non-human DP agrees with the demonstrative pronoun as well as the adjective predicate in gender and number:

(44) haath-ih il-baqarat-u samiin-at-un

this-s.f the-cow-s.f.nom fat-f-s.nom

'This cow is fat'

(45) haat-aan il-baqarat-aan samiin-at-aan

these-dual.f.nom the-cows-dual.f.nom fat-f-dual.nom

'These (two) cows are fat'

However, when the non-human DP is pluralized, the agreeing demonstrative pronoun as well as the adjective predicate show a singular number:

(46) *haa?ulaa? il-Pabqaar-u samiin-aat-un

these-p.m/f the-cows-p.f.nom fat-p.f-nom

'These cows are fat'

(47) haath-ih il-Pabqaar-u samiin-at-un

this-s.f the-cows-p.f.nom fat-f-s.nom

'These cows are fat'

\subsection{Non-Human DPs and Adjectives}

In addition to the adjective predicate in verbless sentences, non-human DPs can also agree with adjectives in noun phrases. Non-human DPs participate in concord with adjectives in number, gender, and Case. The following two examples show adjectival agreement with two singular non-human DPs of which one is masculine and the other is feminine:
(48) Pal-kalb-u s-samiin-u
the-dog-s.m.nom the-fat-s.m.nom
'The fat dog'
(49) Pal-qiTTat-u s-samiin-at-u
the-cat-s.f.nom the-fat-f-s.nom
'The fat cat'

In the same manner, dual non-human DPs participate in concord with their adjectives in number, gender, and Case:
(50) Pal-kalb-aan is-samiin-aan
the-dogs-dual.m.nom
'The (two) fat dogs'
(51) Pal-qiTTat-aan is-samiin-at-aan
the-cats-dual.f.nom the-fat-f-dual.nom
'The (two) fat cats'

When an adjective participates in concord with a non-human plural DP, it always shows a singular number: 
(52) Pal-kilaab-u s-samiin-at-u
the-dogs-p.f.nom the-fat-f-s.nom
'The fat dogs'
(53) Pal-qiTaT-u s-samiin-at-u
the-cats-p.f.nom the-fat-f-s.nom
'The fat cats'
5.4 Non-Human DPs and Relative Pronouns

Relative pronouns agree with the DP to which they refer to in gender and number. Inflection for Case on the relative pronoun is similar to the one on demonstrative pronouns, where Case is marked when the pronoun has a dual number:
(54) Pal-walad-u llathi fi S-Suurat-i
the-boy-nom who-s.m in the-picture-gen

'The boy who is in the picture'
(55) Pal-fataat-u llati fi S-Suurat-i
the-girl-nom who-s.f in the-picture-gen

'The girl who is in the picture'
(56) Pal-walad-aan illathaan fi S-Suurat-i
the-boys-dual.m.nom who-dual.m.nom in the-picture-gen
'The (two) boys who are in the picture'
(57) Pal-fataat-aan illataan fi S-Suurat-i
the-girls-dual.f.nom who-dual.f.nom in the-picture-gen
'The (two) girls who are in the picture'

(58) Pal-awlaad-u llathiin fi S-Suurat-i

the-boys-nom who-p.m in the-picture-gen

'The boys who are in the picture'

(59) Pal-fatayaat-u llaati fi S-Suurat-i

the-girls-nom who-p.f in the-picture-gen

'The girls who are in the picture'

Likewise, singular and dual non-human DPs agree with relative pronouns in Standard Arabic and both categories inflect for gender and number. As before, Case is marked on the relative pronoun only when it has a dual number:
(60) Pal-kitaab-u llathi fawqa T-Taawilat-i
the-book-s.m.nom which-s.m on the-table-gen
'The book which is on the table'
(61) Pas-sayyaarat-u llati fi l-xaarij-i
the-car-f.nom which-s.f in the-outside-gen

'The car which is outside'
(62) Pal-kitaab-aan illathaan fawqa T-Taawilat-i
the-books-dual.m.nom which-dual.m.nom on the-table-gen
'The (two) books which are on the table'
(63) ?as-
the-car-dual.f.nom which-dual.f.nom in the-outside-gen
'The (two) care which are outside' 
However, when the relative pronoun agrees with a non-human plural DP, it always shows a singular number.
(64) Pal-kutub-u

llati
fawqa T-Taawilat-i
the-books-p.f.nom which-s.f on
the-table-gen

'The books which are on the table'

(65) Pas-sayyaaraat-u llati fi 1-xaarij-i

the-cars-p.f.nom which-s.f in the-outside-gen

'The cars which are outside'

\subsection{Non-Human DPs and Pronominal Clitics}

In Standard Arabic, a left-dislocated nominal usually leaves a pronominal clitic in its original position. In this language, the clitic usually agrees with the left-dislocated DP in number and gender:

(66) Pal-fatayaat-u raPay-tu-hunna

the-girls-nom saw-1.s-them-f

'The girls, I saw them'

(67) Pal-Pawlaad-u raPay-tu-hum

the-boys-nom saw-1.s-them-m

'The boys, I saw them'

Likewise, when the left-dislocated element is a non-human singular DP, it leaves a clitic in its base-generated position and agrees with it in number and gender:

(68) Pan-namir-u raPay-tu-hu

the-tiger-s.m.nom saw-1.s-him

'The tiger, I saw it'

(69) Pan-namir-aan rapay-tu-humaa

the-tigers-dual.m.nom saw-1.s-they-dual.m

'The (two) tigers, I saw them'

However, when the left-dislocated DP is a non-human plural, the clitic fails to show plural number agreement. Instead, the clitic appears with a singular feminine marker:
(70) Pan-numuur-u ra?ay-tu-ha
the-tigers-p.f.nom saw-1.s-her
'The tigers, I saw them'

\section{Non-Human DPs and Verbal Anti-Agreement Revisited}

The phenomenon of verbal anti-agreement with non-human plural subjects describes the unexpected and unexplained lack of plural number agreement between the verb and its non-human plural subject in Standard Arabic. The typical instances of verbal anti-agreement that have received extensive investigation are referred to in the literature as "anti-agreement effect" (AAE) (Ouhalla, 1993, 2005). Instances of (AAE) are usually associated with the movement of the subject in pro-drop languages to a sentence-initial position in interrogative sentences, relative clauses and cleft sentences. In these contexts, the verb surfaces with agreement features that do not match the features on the moved subject. However, our discussion here differs from the instances of (AAE) since the domain of verbal anti-agreement in Standard Arabic is declarative sentences where the subject does not need to vacate the TP. Actually, in VS order, the subject is assumed to be in the vP, hence the proposed accounts for instances of (AAE) cannot be applied to the discussion at hand.

Non-human singular DPs can agree with the verb in Standard Arabic in person and gender in VS order. It is difficult to decide whether the singular number on the verb is valued by the singular subject, or if it is a default number on the head T. I assume that it is a default number in this case. This assumption is motivated by the fact that the same verb has a default singular number in VS order with dual and plural DPs:
(71) Pakal-a 1-fa?r-u
1-jubnat-a
ate-3.s.m
the-mouse-m.s.nom
the-cheese-acc 
'The mouse ate the cheese'
(72) Taarad-a
l-kalb-u
1-Paghnaam-a
chased-3.s.m
the-dog-m.s.nom
the-sheep-acc
'The dog chased the sheep'

The examples above can have an alternative SV order with the same agreement values:
(73) Pal-fa?r-u
Pakal-a 1-jubnat-a
the-mouse-m.s.nom ate-3.s.m the-cheese-acc

'The mouse ate the cheese'
(74) Pal-kalb-u
Taarad-a
1-Paghnaam-a
the-dog-m.dual.nom chased-3.dual.m the-sheep-acc
'The dog chased the sheep'

It is to be noticed that non-human dual DPs also show a typical pattern of subject-verb agreement in Standard Arabic where the verb partially agrees with its subject in VS sentences, whereas full subject-verb agreement is established in SV sentences:
(75) a. Pakal-a 1-farr-aan
al-jubnat-a
ate-3.s.m the-mouse-m.dual.nom
the-cheese-acc
'The (two) mice ate the cheese'
b. Pal-fa?r-aan
Pakal-aa
1-jubnat-a
the-mouse-m.dual.nom ate-3.dual.m
the-cheese-acc
'The (two) mice ate the cheese'
(76) a. Taarad-a
1-kalb-aan
chased-3.s.m the-dog-m.dual.nom
the-sheep-acc

$$
\text { al-Paghnaam-a }
$$
'The (two) dogs chased the sheep'
b. Pal-kalb-aan
Taarad-aa
1-Paghnaam-a
the-dog-m.dual.nom
chased-3.dual.m
the-sheep-acc
'The (two) dogs chased the sheep'

The data above show that non-human singular and dual DPs exhibit the same subject-verb agreement asymmetry found with human DPs. However, when non-human DPs are pluralized, they show a different pattern of agreement:
(77) a. Pakal-at il-fi?raan-u l-jubnat-a
ate-3.s.f the-mice-f.nom the-cheese-acc
'The mice ate the cheese'
b. Pal-fi?raan-u Pakal-at il-jubnat-a
the-mice-f.nom ate-3.s.f the-cheese-acc
'The mice ate the cheese'
c. * Pal-firraan-u Pakal-na 1-jubnat-a
the-mice-f.nom ate-3.p.f the-cheese-acc
'The mice ate the cheese'
(78) a. PaYlan-at
il-?ithaaSaat-u
1-xabar-a
broadcast-3.s.f the-radio stations-f.p.nom
the-news-acc

'Radio-stations broadcast the news'
b. Pal-PithaaSaat-u
PaYlan-at
il-xabar-a
the-radio stations-f.p.nom
broadcast-3.s.f the-news-acc 
'Radio-stations broadcast the news'
c. *Pal-PithaaYaat-u
PaClan-na
1-xabar-a
the-radio stations-f.p.nom broadcast-3.p.f the-news-acc
'Radio-stations broadcast the news'

$\begin{array}{clc}\text { (79) a. Taarad-at } & \text { il-kilaab-u } & \text { 1-Paghnaam-a } \\ \text { chased-3.s.f } & \text { the-dogs-f.nom } & \text { the-sheep-acc }\end{array}$

'The dogs chased the sheep'
b. Pal-kilaab-u
Taarad-at
il-?aghnaam-a
the-dogs-f. nom
chased-3.s.f the-sheep-acc
'The dogs chased the sheep'
$\begin{array}{lll}\text { c. }{ }^{*} \text { Pal-kilaab-u } & \text { Taarad-na } & \text { 1-Paghnaam-a } \\ \text { the-dogs-f. nom } & \text { chased-3.p.f } & \text { the-sheep-acc }\end{array}$

'The dogs chased the sheep'

As can be seen from the data above, in SV sentences, the verb seems to partially agree with its subject, showing singular number on the verb while the subject is plural. This seems to pose a serious challenge to the minimalist assumption that only a $\Phi$-complete head $\mathrm{T}$ can have an EPP-feature.

In view of the unavailability of any previously proposed account for this phenomenon in Standard Arabic, I propose two competing accounts which still need further investigation and evidence. The first account builds on the assumption that preverbal subjects in Standard Arabic are Topics (Mohammad, 2000):

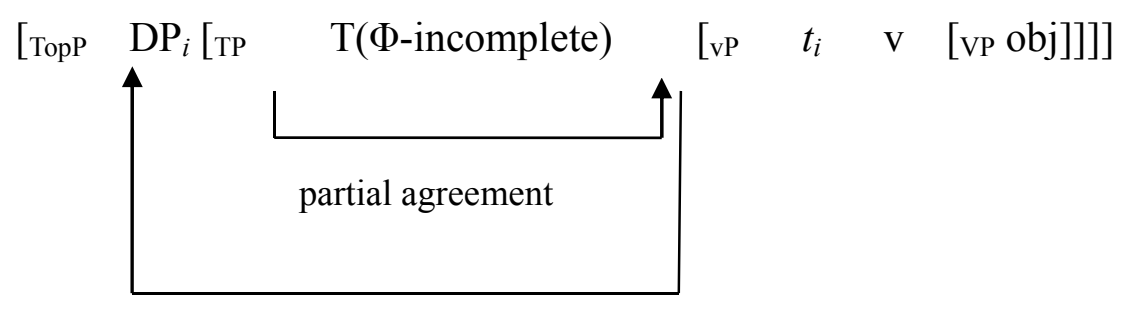

topicalisation

If this assumption is on the right track, it means that the postverbal subject, which is the unmarked position for subjects in this language, establishes agreement via a probe-goal relation (Agree) with $\mathrm{T}$. As a result, the verb shows singular number value (partial agreement), which is the expected default agreement that verbs in this language get when their subject is postverbal. In topicalisation contexts, the subject, after establishing partial agreement with the verb, vacates its base-position in vP to a TopP above the TP, with the verb showing anti-agreeing singular number in SV word order where it is expected to show plural number value.

The second account looks at the featural structure of plural nominals in Standard Arabic in order to understand the inventory of features in non-human plural DPs. It is to be noticed that the formation of plurals in Standard Arabic does not follow a uniform pattern. For example, the plural marker for a masculine DP is different from that of a feminine one. Even the plural morpheme of a masculine DP varies according to the Case of the DP. Thus, while the plural morpheme in English is [-s] for the majority of DPs, the plural morpheme for masculine DPs in Standard Arabic is [-uun] if nominative and [-iin] elsewhere, and the plural morpheme for feminine DPs is [-aat]. This is not the whole story. The mentioned plural markers [-uun/-iin/-aat] are called regular/sound plural markers. In fact, there are irregular/broken plural markers in Standard Arabic which can be attached to masculine and feminine DPs alike. The irregular markers are not pure suffixes, but they vary between prefixes, infixes, and suffixes, and sometimes a mixture of all of them.

To give the reader a taste of this complex system of marking plural on nominals in Standard Arabic, look at the forms of the following singular DPs and compare them with the plural forms: 


$\begin{array}{lrll}\text { (81) a. kitaab } & \text { 'book' } & \text { kutub } & \text { 'books' } \\ \text { b. jidaar } & \text { 'wall' } & \text { judraan } & \text { 'walls' } \\ \begin{array}{l}\text { c. ghiTaa? } \\ \text { 'cover' }\end{array} & \text { PaghTiyah } & \text { 'covers' } \\ \text { d. qalam } & \text { 'pen' } & \text { Paqlaam } & \text { 'pens' }\end{array}$

In his discussion of the formation of plurals in Standard Arabic and why irregular/broken plurals cannot take the regular/sound plural marker, Wright (1967) argues that plural nominals can either refer to collective individuals or distinct individuals; and the logical form of the corresponding nominal usually dictates agreement on the verb. This means that non-human DPs can be assumed to always refer to collective nominals, in the sense that nominals that denote non-humans are not viewed individually, but viewed as a collective unit. Corbett (2004) reiterates the same notion and argues that only individuated nominals, i.e. nominals that are viewed as distinct individuals, can establish plural agreement with the verb.

It is also to be noticed that while non-human singular or dual DPs can be masculine or feminine, non-human plurals are invariably feminine, even if the singular form of the same noun is masculine:
(82) a. Pakal-a l-farr-u l-jubnat-a
ate-3.s.m the-mouse-m.nom the-cheese-acc
'The mouse ate the cheese'
b. Pakal-at il-fi?raan-u 1-jubnat-a
ate-3.s.f the-mice-f.nom the-cheese-acc
'The mice ate the cheese'
c. Pal-farr-u Pakal-a l-jubnat-a
the-mouse-m.nom ate-3.s.m the-cheese-acc
'The mouse ate the cheese'
d. Pal-fiPraan-u Pakal-at il-jubnat-a
the-mice-f.nom ate-3.s.f the-cheese-acc
'The mice ate the cheese'

In addition, a non-human plural DP cannot be replaced by a corresponding plural pronoun. It can be replaced only by a singular pronoun and, importantly, the gender of this pronoun is feminine, suggesting that non-human plurals in Standard Arabic are inherently defective:
(83) a. Pal-fi?raan-u Pakal-at il-jubnat-a
the-mice-nom ate-3.s.f the-cheese-acc
'The mice ate the cheese'
b. *hunna Pakal-at il-jubnat-a
they-fem ate-3.s.f the-cheese-acc
'They (the mice) ate the cheese'
c. *hunna Pakal-na 1-jubnat-a
they-f ate-3.p.f the-cheese-acc
'They (the mice) ate the cheese'

$$
\begin{array}{ccc}
\begin{array}{c}
\text { d. hiya } \\
\text { she }
\end{array} & \text { ate-3.s.f } & \text { the-cheese-acc }
\end{array}
$$

'They (the mice) ate the cheese'

Thus, I argue that non-human plural DPs are inherently singular, and the plural marker in such cases carries morphosyntactic information that does not affect the inherently imposed singular feature value.

But, how does Agree work with non-human DPs? I assume that when the head T is $\Phi$-incomplete, Agree is established between $\mathrm{T}$ and the non-human DP in spec-vP, resulting in partial agreement in person and gender. The number feature on $\mathrm{T}$ is given a default singular value. The subject remains in-situ, and its nominative Case is assigned nominative as a reflex of Agree. Alternatively, when $\mathrm{T}$ is $\Phi$-complete, agreement is established 
between $\mathrm{T}$ and the non-human DP, as before, and the Case of the DP is assigned nominative in-situ. However, since $\mathrm{T}$ is $\Phi$-complete, it will have an EPP-feature to raise the subject to spec-TP. Thus, what appears to be a mismatch in number feature between the verb and the non-human subject in SV sentences in Standard Arabic may not be what it appears to be. In VS sentences, the singular number on the verb is the default value. In SV sentences, the singular number on the verb is the uninterpretable feature on $\mathrm{T}$ that is valued through matching with the interpretable number feature of the DP; and that is why T is $\Phi$-complete here and has an EPP-feature.

\section{Conclusion}

In Standard Arabic, the typical pattern of subject-verb agreement is either to have partial agreement in VS word order or full agreement in SV word order. In this paper, I examine a unique case of verbal anti-agreement in Standard Arabic. The phenomenon in question is the unexpected and unexplained verbal anti-agreement with non-human plural subjects. In this language, when the plural subject denotes non-humans, the verb fails to establish plural agreement with that subject whether the latter is preverbal or postverbal. Non-human DPs refer to nominals which denote any animate life-form, whether worldly or ethereal, other than humans, as well as all inanimate entities, whether concrete or abstract. In spite of the fact that non-human DPs represent the majority of nominals in Standard Arabic, or any language for that matter, the literature on agreement in Standard Arabic has not provided any conclusive explanation to account for their distinct morphosyntactic properties and agreement/anti-agreement patterns.

In this paper, I provide two competing analyses, in need of further investigation and evidence, to account for this phenomenon. In the first analysis, I assume that the preverbal non-human subject is in a topic phrase (TopP) above the TP and not in a subject position, thus the singular number marker on the anti-agreeing verb is the result of establishing partial agreement with the non-human subject in its base-position before movement/dislocation to TopP, which is the default agreement pattern in Standard Arabic. In the second account, I build on Wright's (1967) notion of 'collective vs. distinct individuals' and Corbett's (2004) notion of 'individuated nominals'. They both argue that plural nominals can either refer to collective individuals or distinct individuals; subsequently the intended referent dictates agreement on the verb. Thus, I argue that non-human plural subjects are collective nominals that are not individuated, therefore they are inherently singular and the plural marker in this case carries morphosyntactic information that does not affect the inherently imposed singular feature.

In particular, I argue that when $\mathrm{T}$ is $\Phi$-complete, agreement is established between $\mathrm{T}$ and the non-human subject DP, and the Case of the DP is assigned in-situ. However, since T is $\Phi$-complete, it will have an EPP-feature to raise the subject to spec-TP. Under this account, the preverbal subject is obviously in a subject position. Crucially, I assume that in SV word order with non-human DPs the singular number on the anti-agreeing verb is valued through matching with the inherently imposed singular number of the DP.

\section{Acknowledgement}

The author gratefully acknowledges Qassim University, represented by the Deanship of Scientific Research, for their financial support for this research No. (3886) during the academic year 1440 H/2018-2019.

\section{References}

Allan, K. (1987). Hierarchies and the choice of left conjuncts (with particular attention to English). Journal of Linguistics, 23, 51-77. https://doi.org/10.1017/S0022226700011038

Aoun, J., Benmamoun, E., \& Sportiche, D. (1994). Agreement, word order, and conjunction in some varieties of Arabic. Linguistic Inquiry, 25(2), 195-220.

Benmamoun, E. (2000). The Feature Structure of Functional Categories: A comparative study of Arabic dialects. Oxford: OUP.

Berg, V. D. (1989). A Grammar of the Muna Language (Verhandelingen van het Koninklijk Instituut voor Taal-, Land- en Volkenkunde, p. 139). Dordrecht: Foris.

Chomsky, N. (2000). Minimalist inquiries: The framework. In Step by Step: Essays on minimalist syntax. In R. Lasnik, M. Martin \& J. Uriagereka (Eds.), honor of Howard (pp. 89-156). Cambridge MA: The MIT Press.

Comrie, B. (1989). Language Universals and Linguistic Typology: Syntax and Morphology. Oxford: Blackwell.

Corbett, G. (2004). Number. Cambridge: CUP.

Csirmaz, A. (2006). Anti-agreement. Features and locality. In J. Costa \& M. Silva (Eds.), Studies on Agreement (pp. 75-98). Amsterdam: John Benjamins. https://doi.org/10.1075/la.86.05csi 
Evans, N. (1995). A-quantifiers and scope in Mayali. In B. Emmon, J. Eloise, K, Angelika \& P. Barbara (Eds.), Quantification in Natural Languages I (Studies in Linguistics and Philosophy 54, pp. 207-270). Dordrecht: Kluwer.

Fassi Fehri. A. (1993). Issues in the Structure of Arabic Clauses and Words. Dordrecht: Kluwer. https://doi.org/10.1007/978-94-017-1986-5

Mensching, G., \& Eva-Maria, R. (2006). Probes: Lack of agreement in Romance. In J. Costa \& M. Silva (Eds.), Studies on Agreement (pp. 173-201). Amsterdam: John Benjamins. https://doi.org/10.1075/la.86.09men

Mohammad, M. (2000). Word order, agreement and pronominalization in Standard and Palestinian Arabic. Amesterdam: Benjamins. https://doi.org/10.1075/cilt.181

Ouhalla, J. (1993). Subject-extraction, negation and the anti-agreement effect. Natural Language and Linguistic Theory, 11(3), 477-518. https://doi.org/10.1007/BF00993167

Ouhalla, J. (2005). Agreement features, agreement and anti-agreement. Natural Language and Linguistic Theory, 23, 655-686. https://doi.org/10.1007/s11049-004-5927-z

Rice, K. (1989). A Grammar of Slave (Mouton Grammar Library 5). Berlin: Mouton de Gruyter. https://doi.org/10.1515/9783110861822

Rizzi, L. (1997). The Fine Structure of the Left Periphery. In L. Haegeman (Ed.), Elements of Grammar: Handbook in Generative Syntax. Dordrecht: Kluwer. https://doi.org/10.1007/978-94-011-5420-8_7

Rizzi, L. (2004). On Some Properties of Subjects and Topics. Ms., University of Siene.

Schuh, R. G. (1989). Number and gender in Miya. In F. Zygmunt (Ed.), Current Progress in Chadic Linguistics: Proceedings of the International Symposium on Chadic Linguistics: Boulder, Colorado, 1-2 May, 1987 (Current Issues in Linguistic Theory 62, pp. 171-181). Amsterdam: John Benjamins. https://doi.org/10.1075/cilt.62.09sch

Shlonsky, U. (1997). Clause Structure and Word Order in Hebrew and Arabic: An Essay in Comparative Semitic Syntax. Oxford: Oxford University Press.

Smith-Stark, T. C. (1974). The plurality split. In W. L. G. Michael, A. F. Robert \& B. Anthony (Eds.), Papers from the Tenth Regional Meeting (Chicago Linguistic Society, April 19-21, 1974, pp. 657-671). Chicago: Chicago Linguistic Society.

Wright, W. (1967). A Grammar of the Arabic Language (Translated from the German of Caspari and Edited with Numerous Additions and Corrections I, 3rd ed. revised by W. Robertson Smith and M. J. de Goeje). Cambridge: Cambridge University Press.

\section{Notes}

Note 1. The following abbreviations will be used in the gloss for the examples throughout the paper: nom $=$ nominative Case, acc $=$ accusative Case, gen $=$ genitive Case, $1=$ first person, $2=$ second person, $3=$ third person, $\mathrm{s}=$ singular number, $\mathrm{p}=$ plural number, $\mathrm{m}=$ masculine, $\mathrm{f}=$ feminine .

\section{Copyrights}

Copyright for this article is retained by the author, with first publication rights granted to the journal.

This is an open-access article distributed under the terms and conditions of the Creative Commons Attribution license (http://creativecommons.org/licenses/by/4.0/). 